\title{
Controlling avian influenza infections: The challenge of the backyard poultry
}

\author{
Munir Iqbal \\ Division of Microbiology, Institute for Animal Health, Compton Laboratory, Compton, Newbury, Berkshire RG20 \\ $7 \mathrm{NN}, \mathrm{UK}$ \\ ${ }^{*}$ Correspondence to: Munir Iqbal, Email: munir.iqbal@bbsrc.ac.uk, Tel: +44 1635 577273, Fax: +44 1635577263
}

Received 13 January 2009, Published online 16 January 2009

J Mol Genet Med (2009), 3(1), 119-120

(C) Copyright The Author: This is an open access article, published under the terms of the Creative Commons Attribution Non-Commercial License (http://creativecommons.org/licenses/by-nc/2.0/uk/). This license permits noncommercial use, distribution and reproduction of the article, provided the original work is appropriately acknowledged with correct citation details.

In recent years the economic damage inflicted by several avian influenza (AI) subtypes (primarily H5N1 and H9N2, but also $\mathrm{H} 7 \mathrm{~N} 1, \mathrm{H} 7 \mathrm{~N} 3, \mathrm{H} 7 \mathrm{~N} 7$ ) on the commercial poultry industry and backyard poultry is beyond simple calculation. In response to the continued losses suffered by commercial poultry producers large scale vaccination has been introduced in many affected countries for the commercial sector but in many areas of the world no adequate AI control has been implemented for backyard poultry. In the majority of cases, vaccination has resulted in increased resistance to the field virus challenge, prevented illness, reduced the death rate and limited contamination of the environment (Sims, 2007; Peyre et al, 2009). These measures could ultimately reduce transmission within poultry, reduce the incidence of $\mathrm{H} 5 \mathrm{~N} 1$, and so reduce the risk of virus spread from birds to humans. Unfortunately, on the grounds of cost, the use of vaccine mainly remains restricted to the commercial poultry operations and few efforts have been made to effectively control avian influenza in backyard poultry. Thus backyard poultry have become a constant reservoir for $\mathrm{H} 5 \mathrm{~N} 1$ transmission and so pose a threat to the commercial poultry industry and indeed to public health.

Backyard poultry keeping in developing countries is one of the major contributors towards the provision of both income and livelihood for many rural households: It is not simply a 'hobby' activity. Due to low cost and rapid turnover almost every household keeps a small flock of poultry, which is usually reared by the women and children. Backyard poultry provide both meat and eggs and, in times of hardship, may make the difference between life and death. But now this life and death equation has an additional variable - the risk of human infection with avian influenza viruses, particularly with the H5N1 sub-type (Mumford et al, 2007; Peiris et al, 2007).
Backyard poultry rearing in many rural communities is a way of life that has not been changed for centuries. Chickens roam freely within the vicinity of the house during the day but at night are kept inside the house often in the living quarters. Therefore, the intimacy between households and chicken is such that it is very hard to avoid direct or indirect contamination of household food and water. The majority of backyard poultry households may be ignorant of basic biosafety measures and of the potential risk posed by animal diseases to humans. Sick birds may be handled, sold, slaughtered and consumed without considering that the infection that made the chicken sick potentially may also be lethal to man.

There is no doubt that there should be a greater emphasis on the education of rural communities in developing countries in regard to the danger of zoonotic diseases, but it is essential also to protect their livelihood by protecting their livestock. In the case of backyard poultry, disease prevention measures are rare and high mortality rates are common. However, the situation has become worse due to widespread dissemination of highly pathogenic avian influenza viruses (HPAI) in recent years. Although biosecurity is one of the major factors in protecting poultry from AI infection, it is not practicable to implement many improved biosecurity measures in backyard poultry flocks. Therefore, an effective alternative is to increase the resistance of birds by implementation of regular and comprehensive AI vaccination strategies.

It is widely accepted that vaccination against HPAI infection in backyard poultry is very difficult to implement and to sustain in the long term. The majority of developing countries affected by outbreaks of $\mathrm{H} 5 \mathrm{~N} 1$ virus do not have 
sufficient resources to even consider vaccination of backyard poultry as an option. Recently, both governmental organisations and commercial companies have started to invest in the development of effective and efficacious AI vaccines for commercial large scale poultry production systems. Nevertheless the real challenge for all of us is to protect backyard poultry, which are reared exclusively by poor sections of the society. Until we change this balance, HPAI (H5N1) viruses will continue to spread and without greater efforts to control AI in the backyard poultry flock the threat of a human pandemic from avian influenza viruses could never be considered a remote scenario.

\section{REFERENCES}

Mumford E, Bishop J, Hendrickx S, Embarek PB, Perdue M. 2007. Avian influenza H5N1: risks at the human-animal interface. Food Nutr Bull, 28, S357-363.

Peiris JS, de Jong MD, Guan Y. 2007. Avian influenza virus (H5N1): A threat to human health. Clin Microbiol Rev, 20, 243267.

Peyre M, Fusheng G, Desvaux S, Roger F. 2009. Avian influenza vaccines: A practical review in relation to their application in the field with a focus on the Asian experience. Epidemiol Infect, 137, 1-21.

Sims LD. 2007. Experience in control of avian influenza in Asia. Dev Biol (Basel), 130, 39-43. 